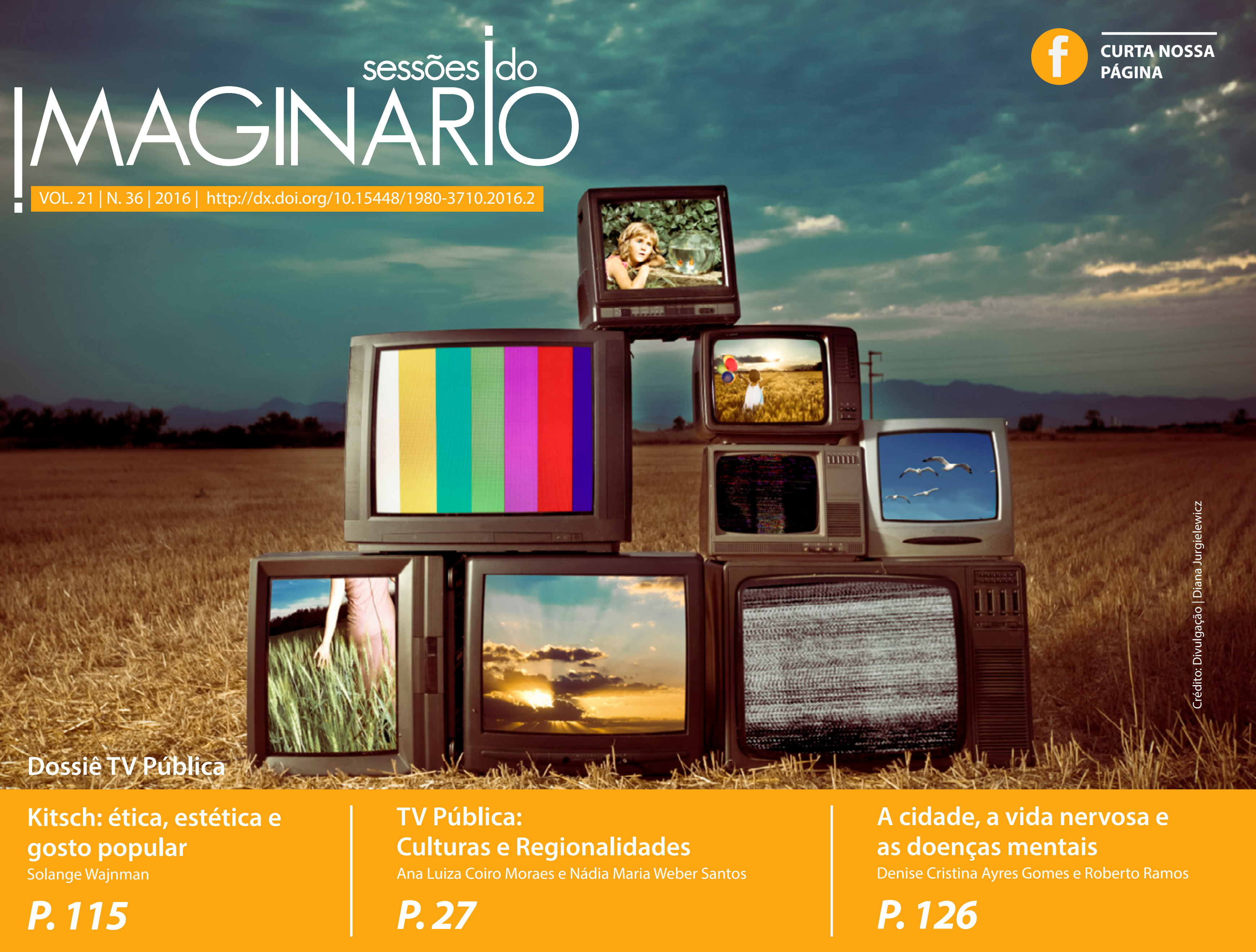




\section{Televisão e identidade gaúcha no Oeste Catarinense ${ }^{1}$}

\section{Television and gaucho identity in the West of Santa Catarina}

Flavi Ferreira Lisbôa Filho'

Franscesco Flavio da Silva ${ }^{3}{ }^{3}$

\section{Resumo}

Apesar de pertencer ao estado brasileiro de Santa Catarina, o município de Chapecó apresenta fortes traços da cultura gaúcha, que teve importante papel na colonização da região. Na atualidade estes traços culturais circulam pela mídia local, em especial pelo quadro esportivo diário do telejornal Jornal Almoço da RBS TV Chapecó, foco de nossa análise. A presença de conteúdos relacionados às duas principais equipes de futebol do Rio Grande do Sul (Internacional e Grêmio) contrastam com a recente ascensão nacional do time de futebol local, a Chapecoense. Com o aporte teórico-metodológico dos Estudos Culturais, buscamos compreender como a cultura e a identidade gaúcha se relacionam na atualidade na cidade conhecida como a capital do Oeste catarinense. Nos apropriamos da hipótese cultural da Estrutura de Sentimento de Raymond Williams para perceber como a cultura se transforma e se relaciona como modo de vida.

\section{Palavras-chave}

Televisão; identidade; estudos culturais; estrutura de sentimento; gauchidade.

\section{Abstract}

Although belonging to the Brazilian state of Santa Catarina, Chapecó has strong features of the gaucho culture, which played an important role in the colonization of the region. Nowadays these cultural traits are circulating in the local media, especially the daily sports framework at the TV news Jornal do Almoço, of RBS TV Chapecó, focus of our analysis. The presence of contents related to the two main soccer teams in Rio Grande do Sul (Internacional and Grêmio) contrast with the recent local soccer team national rise, Chapecoense. With the theoretical and methodological contribution of Cultural Studies, we seek to understand how culture and the gaucho identity relate today in the city known as the capital of West Santa Catarina. We appropriate the cultural hypothesis of the Structure of Feeling, by Raymond Williams, to see how culture is transformed and related as a lifestyle.

\section{Keywords}

TV; identity; cultural studies; feeling structure; gauchidade. 


\section{Considerações introdutórias}

A cidade de Chapecó fica na divisa entre os estados brasileiros de Santa Catarina e Rio Grande do Sul e é conhecida pela recente urbanização e potencial econômico, bem como pela presença da cultura gaúcha como consequência da imigração. O município vive um momento pulsante, de mudança de paradigmas e do surgimento de novos questionamentos na esfera social, assim como na constituição da identidade dos sujeitos. A identidade é tratada neste trabalho como um fenômeno instável, passível de crise, definida por Hall (2006, p. 38) como:

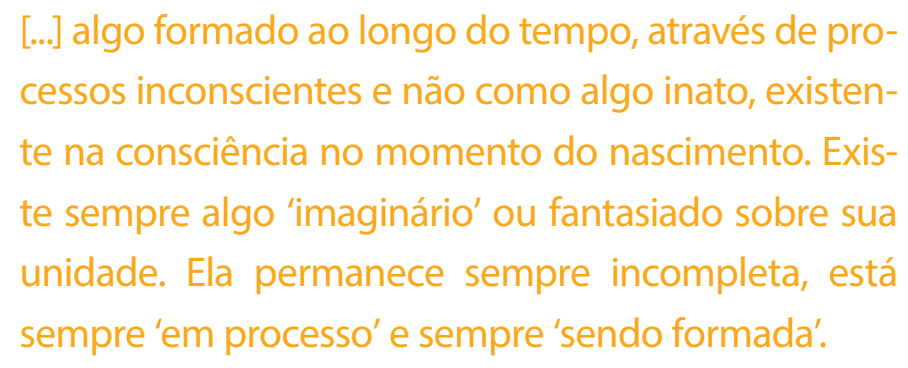

Nas últimas décadas, é notável a transição de um status de "município interiorano colonizado por gaúchos" para a condição de capital do Oeste catarinense, referência nacional na agroindústria, associativismo e também no esporte (pelas recentes conquistas da equipe de futebol da cidade - a Chapecoense).

Assim, o tema desta pesquisa trata das interações culturais que ocorrem no município de Chapecó, em especial as relacionadas ao telejornalismo, haja vista sua presença no cotidiano de milhares de chapecoenses. Estas interações são fundamentais para dar conta do nosso objetivo geral, que é perceber como a identidade gaúcha se manifesta na mídia chapecoense, atuando sobre a compreensão da região e de si por parte dos su- jeitos, (re)configurando identidades. Em meio à complexidade da teia cultural, buscamos pistas que nos ajudem a identificar as recentes transformações identitárias presentes nos conteúdos midiáticos.

Selecionamos o telejornal Jornal do Almoço, produzido e veiculado pela RBS TV de Chapecó, como objeto de nossa análise, mais especificamente o quadro esportivo do programa, o qual acreditamos, como hipótese, carregar em seus conteúdos e produção elementos fundamentais para entender como a cultura gaúcha se manifesta na atualidade. Temos como hipótese deste trabalho que os quadros esportivos tendem a exibir alinhamentos editoriais próprios da emissora e da produção jornalística, mas também costumam atender às necessidades do público, se provando importantes fontes de pesquisa para a análise cultural.

A base teórica e metodológica desta pesquisa está ancorada nos Estudos Culturais para os conceitos de cultura, identidade e representação, assim como de Estrutura de Sentimento (Williams, 2003) para compreender a emergência de novas manifestações culturais, assim como o residual e o dominante.

\section{Cultura e estrutura de sentimento}

Distante dos locais em que a cultura gaúcha originariamente é comum, como a Argentina, o Uruguai e o estado do Rio Grande do Sul, o município catarinense de Chapecó não faz parte dos territórios em que historicamente se faz referência à presença do gaúcho. Porém, em seu espaço, é possível perceber a existência do que aqui identificamos como gauchidade 4 . Como a identidade, a cultura não é um conceito estanque. $O$ processo de formação cultural, de acordo com Hall (2006) envolve deslocamentos de sentidos. Sobre eles, o autor afirma que:
Há sempre algo descentrado no meio cultural [...], na linguagem, na textualidade, na significação; há algo que constantemente escapa e foge à tentativa de ligação, direta e imediata, com outras estruturas [...] dos textos como fontes de poder, da textualidade como local de representação e de resistência, nenhuma destas questões poderá jamais ser apagada dos estudos culturais (Hall, 2006, p. 199).

Raymond Williams (1992) apresenta a noção de cultura como uma espécie de resposta aos acontecimentos que vivemos, e como um esforço por compreender, interpretar e apreciar as mudanças provocadas na sociedade. Tentar compreender um produto cultural exige que se faça um detalhamento interno e externo dele, identificando as diferentes relações com as forças sociais e suas instituições e tradições que esse produto acaba por suscitar.

A cultura estabelece conexões entre todos os elementos significados pelos sujeitos, mas, de acordo com o autor, para que isso possa ser compreendido, é necessário que esses elementos sejam pensados e analisados em sua totalidade social complexa. Isso implica contextualizá-los (os elementos) em meio a trocas gerais e em relação aos laços de localidade (Williams, 1992).

Estamos então definindo estes elementos como uma 'estrutura': como uma série, com relações internas específicas, ao mesmo tempo engrenadas e em tensão. Não obstante, estamos também definindo uma experiência social que está ainda em processo, com frequência ainda não reconhecida como social, mas como privada, idiossincrática, e mesmo isolada, mas que na análise (e raramente de outro modo) 
tem suas características emergentes, relacionadoras e dominantes e na verdade suas hierarquias específicas (Williams, 1979, p. 134).

Com base em estudos focados na compreensão de processos de mudança social a partir da arte e da literatura, Raymond Williams (2005) desenvolveu o conceito de "Estrutura de Sentimento", como hipótese cultural. Para ele, o artista nunca expressa um ponto de vista isolado ou individual, mas sim uma representação do ponto de vista do grupo social ao qual pertence. $\mathrm{O}$ autor desenvolveu sua teoria em duas produções: em The Long Revolution, de 1961, onde apresenta a importância da ideia de Estrutura de Sentimento para a análise cultural; e em Marxismo e Literatura, de 1979, onde apresenta os capítulos "Estruturas de Sentimento" e "Dominante, residual, emergente", que servem de base analítica para este estudo.

De forma abrangente, esta hipótese cultural atua refletindo sobre tempo e lugar específicos, onde pessoas vivem suas experiências, sendo a "cultura de um período: o resultado vital e específico de todos os elementos da organização geral"5 (Williams, 2003, p. 57, tradução nossa). Desta forma, o autor afirma que o senso de uma geração, por exemplo, é correspondente aos processos de experiência social e das relações sociais em determinado período/contexto.

Uma geração pode formar a sua sucessora, com razoável êxito, no caráter social ou no padrão cultural geral, mas a nova geração terá sua própria Estrutura de Sentimento, que, aparentemente, não 'procede' de nenhuma parte. Posto que neste caso, de maneira mais característica, a organização cambiante se representa no organismo: a nova geração responde a seu modo ao mundo único que herda, leva a cabo muitas continuidades que podem ser rastreadas e reproduz numerosos aspectos da organização que é possível descrever, mas de certo modo sente toda sua vida de forma diferente e molda a sua res posta criativa a uma nova Estrutura de Sentimento (Williams, 2003, p. 57-58).

Dominante, emergente e residual são categorias analíticas que atravessam tempo e história da prática social, revelando os elementos que constituem determinada cultura. Segundo Williams (2011, p.53), “[...] há um sistema central de práticas, significados e valores que podemos chamar especificamente de dominante e eficaz", independente da sociedade e do período. A cultura dominante está continuamente ativa e adaptando-se, sendo ela flexível e abrangente. É o modelo estabelecido e reconhecido pelos indivíduos, legitimando e consolidando através de práticas a si própria enquanto referência de uma determinada cultura.

Os conflitos sociais, as interações e inter-relações é que acabam por dar a dimensão crítica daquilo que é produzido culturalmente. Na visão de Williams (1979), nenhuma cultura dominante é capaz de esgotar tudo o que envolve ou é produzido pelos sujeitos, deixando sempre resíduo ou o que se pode chamar por cultura residual. Formado no passado, o residual ainda atua na sociedade podendo se opor ao dominante ou conviver com ele.

Por 'residual' quero dizer que algumas experiências, significados e valores que não podem ser verificados ou não podem ser expressos nos termos da cultura dominante são, todavia, vividos e praticados como resíduos - tanto culturais como sociais - de formações sociais anteriores (Williams, 2005, p. 224).

O terceiro elemento a ser explorado, o emergente, tensiona a relação entre dominante e residual, pois gera novos valores e ideias que contrapõem o que está estabelecido na cultura vigente. Por "emergente" quero dizer, primeiramente, que novos significados e valores, novas práticas, novos sentidos e experiências estão sendo continuamente criados (Williams, 2005, p. 224). O autor credita como emergente todas "[...] as áreas da experiência, aspiração e realização humanas que a cultura dominante negligencia, subvaloriza, opõe, reprime ou nem mesmo pode reconhecer" (Williams, 1979, p. 127).

As estruturas de sentimento estão sempre refletidas nas alterações contidas na produção cultural e são capazes de modificar a tradição e a própria organização social. Quando identificamos o desenvolvimento de uma identidade gaúcha em meio à sociedade chapecoense, podemos dizer que nesta localidade estão presentes tais estruturas de sentimento, contribuindo para a diversidade cultural local.

\section{Representação identitária}

\section{e a televisão em SC}

Assim como a identidade, o conceito de representação também faz parte dos processos culturais, sendo uma associada à outra. A representação midiática exercida pela televisão, e em especial neste estudo o telejornalístico, perpassa pela amplitude dos significados gerados diariamente para os telespectadores, através dos símbolos e da linguagem. Ela carrega um conjunto de significados, tornando possível construir um sujeito dando sentido à identidade, como explica Hall: 
Representação é usar a linguagem para dizer algo significativo ou representar o mundo de forma significativa para outrem [...]. A representação é parte essencial do processo pelo qual o significado é produzido e intercambiado entre os membros de uma cultura. De fato, envolve a utilização da linguagem, de sinais e imagens que significam ou representam coisas, mas longe de ser um processo simples ou direto [...] (1997, p. 15 apud Enninger, 2015, p. 36).

A utilização de imagens, sinais e linguagem caracteriza a televisão como construtora de sentidos, evidenciando a importância de analisar suas mensagens e como elas contribuem para a construção/reforço de uma identidade. Como instituições comerciais, que visam lucro a partir do volume de audiência, emissoras de televisão focam suas produções no intuito de atrair o público. Seus processos de produção são direcionados através de enunciados capazes de contribuir para a construção, manutenção ou transformação de uma identidade regional, dentro da área de abrangência e sua transmissão.

A abrangência do veículo possibilita ao mesmo tempo uma influência maior na tomada de decisões de seu público, tudo porque os telespectadores assíduos a têm como uma fonte de todo saber. Seu poder de persuasão é tão grande que não há divergências quando determinado assunto é mostrado na televisão. [...] A televisão, na verdade, constrói uma realidade, na forma de um sistema de representações sociais (Maia, 2002, p. 10).
Na história do estado de Santa Catarina percebe-se que no início do século XX há uma leva significativa de imigrantes, vindos do estado vizinho Rio Grande do Sul em busca de novas terras para se estabelecer e produzir Eles trouxeram consigo mais do que elementos residuais de uma cultura alemã e italiana de seus antepassados europeus, implantaram uma nova tradição adquirida/construída no sul do continente americano.

A migração dirige-se primeiro para os estados da região sul do Brasil, migrando para o Oeste e Meio-Oeste de Santa Catarina, assim como para o Sudoeste e Extremo-Oeste do Paraná. O fato dos migrantes optarem por Santa Catarina e Paraná deu-se por conta das companhias colonizadoras desses estados pertencerem, em sua maioria, a empresários do Rio Grande do Sul, que, diante da dificuldade em obter novas áreas para a comercialização naquele estado, passaram a atuar na venda das terras desocupadas no Oeste catarinense onde o governo concedia a estas empresas terras devolutas, em troca da construção de estradas transformando-os nos principais responsáveis pelo processo de recrutamento e povoamento do Oeste de Santa Catarina (Silva, 2010, p. 57)

Justamente neste período de expansão migratória, se desenvolveu no Rio Grande do Sul, e por vários pontos do país onde havia imigrantes gaúchos, a influência de sua cultura, ratificada mais tarde pela expansão do Movimento Tradicionalista Gaúcho (MTG), difundido por meio de centenas de Centros de Tradição Gaúcha - os CTGs. Em 2010 segundo dados da Confederação Brasileira de Tradições Gaúchas, o estado sul-rio-grandense possuía formalmente registrados 1.731 CTGs e Santa Catarina 562, se colocando como o estado brasileiro com o maior número de CTGs fora do Rio Grande do Sul. Essa cultura inventada ${ }^{6}$, como defendida por alguns autores, e intensamente reforçada, se enraizou através da construção do imaginário do gaúcho, servindo mais como uma representação de nação gaúcha, independe de território, religião ou etnia.

A história de Santa Catarina também possui marcas de outra migração do Rio Grande do Sul, a da comunicação. Mas para melhor compreender o movimento migratório e o contexto em que se deu esse fenômeno, cabe aqui fazer um breve relato da trajetória da chegada da televisão ao Brasil, passando primeiro pelo Rio Grande do Sul, depois em Santa Catarina e por fim a Chapecó.

Em 1950 chega ao Brasil um dos inventos que mudou para sempre a concepção de comunicação de massa no mundo. A televisão, trazida por Assis Chateaubriand para a exibição do primeiro canal de TV da América Latina, a extinta TV Tupi de São Paulo, fez com que rapidamente surgissem outras emissoras nacionais como a Record, TV Excelsior e a TV Paulista ${ }^{7}$. Logo a televisão passou a ser uma fórmula mágica para a venda de produtos - todos os produtos.

Se nacionalmente a televisão se espalhou rapidamente, em outras regiões do país não foi diferente. No Rio Grande do Sul (RS), por exemplo, o próprio Chateaubriand comandou a TV Piratini em Porto Alegre, fundada em 1959. Alguns anos depois, em 1962, o empresário e jornalista Maurício Sirotsky Sobrinho, funda em Porto Alegre a TV Gaúcha, que mais tarde se tornaria o Grupo RBS (Rede Brasil Sul) ${ }^{8}$. Já no estado de Santa Catarina (SC), até o ano de 1979, existiam apenas duas emissoras, a TV Cultura e a TV Coligadas. Nesse período o Grupo RBS expandiu sua transmissão com a criação da TV Catarinense, em Florianópolis. 
Assim, da mesma forma como os colonos do século passado cruzaram o Rio Uruguai, que marca a divisa entre Santa Catarina e Rio Grande do Sul, em busca de novas oportunidades, também os veículos de comunicação televisivos o fizeram, em busca de novos territórios para transmitir seus conteúdos. A influência cultural gaúcha se manteve viva no início do século XXI, não apenas para os nascidos em solo sul-rio-grandense, mas viva e ativa em terras catarinenses.

A entrada do Grupo no estado foi estratégica e devido ao grande investimento, fora do alcance das outras emissoras locais, os gaúchos são considerados os pioneiros da televisão. Eles trouxeram consigo costumes e práticas típicas da cultura gaúcha, implícitas no fazer televisivo, disseminando-as no solo catarinense rapidamente.

Somente o Grupo RBS, que já tinha um padrão testado no Rio Grande do Sul de produção regional, não trouxe inovações nesta concepção, muito embora seja apontado como inovador na forma como administrou e implantou a empresa em Santa Catarina. Do ponto de vista dos formatos dos programas, repetiu as fórmulas de sucesso no estado gaúcho, que já possuía uma certa aproximação do padrão de produção da TV Tupi e, mais tarde, da própria Rede Globo (Cavenaghi e Emerim, 2014, p. 142).

Em apenas três anos de sua chegada, a RBS já contava com outras cinco emissoras e, hoje, a rede atende todas as regiões do estado, comandando seis emissoras, conhecidas como RBS Joinville, RBS Criciúma, RBS Chapecó, RBS Florianópolis, RBS Blumenau e a RBS Centro-Oeste.

As práticas de produção de conteúdos executadas no RS pelo Grupo passam a estar cada vez mais presentes no cotidiano dos catarinenses. Elas tornam-se fortes referências midiáticas para o novo sistema de produção que se instalava em SC. Os primeiros profissionais que atuaram na implantação das emissoras no estado deixaram registros que relatam a influência da cultura gaúcha na seleção dos conteúdos dos primeiros programas televisivos locais. Os gaúchos da televisão encontraram no Oeste catarinense uma região habitada também por imigrantes do estado vizinho, que mantiveram a sua gauchidade.

É neste cenário que esta pesquisa busca entender como, através das notícias esportivas do Jornal do Almoço, produzidas pela emissora catarinense RBS TV Chapecó, a identidade gaúcha se manteve presente através do bloco esportivo nas informações sobre Grêmio e Internacional, em contraposição ao time da cidade, a Chapecoense. O programa telejornalístico Jornal do Almoço (JA) é exibido há mais de 30 anos no estado. No município de Chapecó, o telejornal é o mais antigo.

\section{Jornal do Almoço em Chapecó: análise}

da produção esportiva

Este capítulo apresenta um breve histórico da RBS TV Chapecó e alguns detalhes que salientam a presença gaúcha durante e após sua instalação na região. Na sequência está a análise do quadro esportivo do Jornal do Almoço Chapecó, seguindo o aporte metodológico dos Estudos Culturais e a hipótese cultural da Estrutura de Sentimento.

A licença para operar um canal em Chapecó foi concedida a Darci Lopes, fundador da TV Cultura de Florianópolis que, mesmo antes do início das operações, teve o canal vendido para Petrelli, colocando no ar, em 23 de abril de 1982, a TV Cultura de Chapecó exibindo a programação do SBT. Um ano depois do início das operações, Mário Petrelli vende a emissora para o Grupo RBS (Cavenaghi e Emerin 2014, p. 141).

A RBS TV Chapecó possui em sua grade de programação diária local, desde 1997, a produção de quatro blocos do JA, sendo um deles produzido por Florianópolis. Após esta pesquisa, em 2015, a emissora de Chapecó passou a exibir todos os quatro blocos de Chapecó, divulgando diariamente alguns poucos conteúdos produzidos (reportagens, boletins, previsão do tempo) por outras sucursais, inclusive da cabeça de rede Florianópolis. Antes, o telejornal era todo apresentado de Florianópolis, contando com conteúdos produzidos na Capital e também pelas sucursais do estado. O JA é um programa informativo jornalístico e conta com aproximadamente 45 minutos de duração com informações principalmente regionais e estaduais, e em menor proporção com temas nacionais e internacionais.

Apesar das mudanças de formato, da evolução tecnológica, do surgimento de novas gerações de telespectadores e o passar de três décadas, a programação jornalística da RBS TV Chapecó manteve no JA o segundo bloco de notícias destinado à editoria esportiva. Essas informações iniciaram a reprodução e difusão de informações relacionadas aos principais times do futebol gaúcho, Internacional e Grêmio, para alimentar uma paixão que cruzou a divisa do Rio Uruguai junto com os imigrantes. Como apresentam Severo e Gomes (2009) apud Cavenaghi e Emerim (2014) em seu relato histórico sobre a chegada das primeiras emissoras de televisão a Santa Catarina:

Severo e Gomes registram um depoimento de Mário Motta, apresentador da emissora ${ }^{9}$ nesta época. 
que demonstra a influência do jornalismo gaúcho na programação da TV lageana: "eventualmente recebíamos por fitas, via ônibus de um dia para o outro, reportagens sobre o Inter, sobre o Grêmio, sobre o Campeonato Gaúcho que eles mandavam como colaboração" (Cavenaghi; Emerim apud Severo; Gomes, 2014, p. 218).

O Jornal do Almoço de Chapecó conta com um casal de apresentadores, e no bloco esportivo, com aproximadamente 8 minutos diários de duração, as notícias são comunicadas por um terceiro apresentador, que também exerce o papel de comentarista esportivo. Para o corpus de análise, foram selecionados os blocos de esporte do JA de 27 de janeiro a 02 de fevereiro de 2015 (seis programas), nos período que compreende a primeira rodada dos campeonatos estaduais, abrangendo tanto a preparação quanto o resultado dos jogos. Esta opção foi tomada após uma pesquisa preliminar que constatou a forte característica regional dos campeonatos estaduais, gerando naturalmente um maior interesse para os habitantes das respectivas regiões pelos resultados e fatos inerentes. Alguns estados brasileiros recebem a programação esportiva nacional da Rede Globo de Televisão, que em diversos programas exibe um resumo dos principais jogos estaduais pelo Brasil. Cabe então, aos telejornais locais, aprofundar as informações das demais equipes envolvidas.

Neste contexto, onde a cultura local hegemônica agrupa elementos simbólicos diversos e talvez controversos, é que iremos aplicar a hipótese da Estrutura de Sentimento de Williams (2005). Pretendemos identificar na difusão de conteúdos do bloco esportivo do JA de Chapecó, elementos culturais que remetam à gauchidade.

Além das notícias sobre a dupla Gre-Nal, esse bloco também apresenta as informações do esporte amador da região, e o time de Chapecó, a Associação Chapecoense de Futebol - a Chapecoense ${ }^{10}$. Isso faz com que o município de Chapecón 11 viva uma situação ímpar, onde traços da cultura gaúcha persistem em solo catarinense constituindo diferentes identidades, e que têm na paixão pelo futebol uma forma de representação clara das transformações culturais da região.

Embora a Chapecoense não possuísse representatividade nacional nos seus primórdios, como a dupla Gre-Nal, o clube de Chapecó atingiu o ápice da sua expressividade no cenário futebolístico brasileiro em 2014 e 2015 ao acessar e se manter na Série A do futebol brasileiro, ao lado da elite dos clubes nacionais. Embora tenha conquistado quatro Campeonatos Catarinenses, uma Copa Santa Catarina e os Campeonatos Brasileiros das Séries $D, C$ e B, o clube sempre dividiu os holofotes no estado com outros quatro times catarinenses: Joinville, Criciúma, Avaí e Figueirense.

A rivalidade entre as cinco equipes catarinenses é forte, muito embora, em nossa análise de seis blocos em datas sequenciais, não houve espaço significativo atribuído às demais equipes catarinenses. No dia 29 de janeiro o apresentador cita objetivamente o jogo entre Criciúma e Guarani, que ocorreria no fim de semana seguinte. No dia 30 de janeiro é exibido no bloco de esporte uma reportagem produzida pela RBS TV de Joaçaba (sucursal de Lages) mostrando a preparação do Internacional de Lages, que enfrentará a Chapecoense na estreia do Campeonato Catarinense. No dia 31 de janeiro, início do campeonato estadual, as demais equipes de Santa Catarina são citadas objetivamente em nota contendo os confrontos, horário, local e arbitragem de cada jogo. Já no dia 02 de fevereiro é exibida no quadro de esporte uma reportagem produzida pela equipe da RBS TV de Florianópolis sobre o jogo Joinville e Avaí, apresentado como "clássico". Na mesma edição imagens rápidas são exibidas do jogo entre Guarani e Criciúma, Metropolitano e Marcílio Dias, com descrição dos principais fatos e lances pelo apresentador. $\mathrm{O}$ jogo entre Figueirense e Atlético de lbirama também é citado, mas sem imagens. Em resumo, podemos afirmar que nestes seis dias de acompanhamento do bloco de esporte do Jornal do Almoço, as demais equipes catarinenses receberam, em média, o menor espaço dos blocos, se comparados à dupla Gre-Nal e Chapecoense.

No bloco de esporte em questão, também se percebe que as informações e referências à Chapecoense ocupam mais do que o dobro do tempo do que o destinado à dupla Gre-Nal. Com menor espaço, as equipes gaúchas ocuparam entre um terço e dois quintos do bloco de esporte, o que demonstra pelo menos duas preocupações por parte da produção do programa: a primeira é a de não sobrepor o espaço da dupla Gre-Nal sob o espaço destinado à Chapecoense, time da casa e hegemonicamente maior detentor dos holofotes; e a segunda preocupação está em manter uma presença fixa de informações de Internacional e Grêmio no telejornal. Claramente, durante a análise do corpus, o espaço dedicado à dupla Gre-Nal é maior do que o espaço dedicado às demais equipes de Santa Catarina. O fato do Jornal do Almoço de Chapecó exibir informações rotineiras sobre Chapecoense, Grêmio e Internacional, ignorando o dia a dia, o corriqueiro das demais equipes catarinenses, evidencia a profunda relação entre a produção da emissora de televisão e a sociedade chapecoense com as equipes do Rio Grande do Sul. É perceptível o foco da emissora em direcionar seu olhar de produção e reprodução para 
aquilo que acredita ser o mais importante para a sociedade da região Oeste de Santa Catarina. Esta característica dominante cria uma zona de tensão com o residual presente na condição de Chapecó pertencer ao Estado de Santa Catarina. O "ser catarinense" nem sempre está ligado às "coisas de Santa Catarina", mas sim as do Oeste do estado e as do Rio Grande do Sul, simultaneamente, pelo menos na semana analisada do quadro de esporte da RBS TV Chapecó.

Este fenômeno, quase bairrista, também é estimulado pelo sistema de produção da RBS TV, que divide suas emissoras por região e lhes imbui da tarefa de cobri-las, abrindo espaço para questões do estado e do país quando necessário. Porém, essa "região" de cobertura ultrapassa divisas estaduais, no caso de Chapecó, refletindo fenômenos culturais residuais, dominantes e emergentes.

Fica clara a característica dominante da cultura de produção da RBS TV Chapecó em manter a presença rotineira das equipes gaúchas na programação, pois se trata de uma prática persistente e repetitiva, fixada. Por outro lado, esta presença apresenta um elemento residual, pois advém de uma prática adquirida no passado, ainda da instalação da emissora pioneira na região e que persiste até os dias de hoje.

Este fenômeno também pode ser caracterizado como emergente, se visto sob a ótica dos nascidos em solo catarinense, por exemplo, e que não se identificam com a cultura gaúcha. Em todas as sociedades, sujeitos desenvolvem identidades distintas e únicas, que se agrupam em casos onde comungam valores simbólicos. Assim também, existem aqueles que não compartilham com os demais, e que na busca por uma identidade com bases territoriais, se veem invadidos por uma cultura que não é legítima de seu território ou estado. O emergente, neste caso, está na introdução de novos valores, significados e práticas que não são os ditos "tradicionais" ou "essenciais" do estado catarinense.

Outro aspecto dominante está na presença de gaúchos e descendentes, e também de torcedores de Inter e Grêmio em Chapecó que acabam por reforçar o caráter hegemônico destes conteúdos nesta região. O público da emissora, que é alvo das estratégias de atração, negocia com o telejornal para que se mantenha assíduo enquanto telespectador. Este fenômeno gera sentidos consensuais que buscam a aproximação do público através de conteúdos específicos, no caso da dupla Gre-Nal.

O futebol, por si só, é referência de uma cultura dominante, visto que compõe aspectos sociais, culturais, atrelados a bens de consumo e simbólicos. Este mesmo futebol, que está presente em praticamente todos os noticiários nacionais, tem na televisão um grande propulsor capaz de reunir e agrupar uma sociedade tão diversa quanto a brasileira. Marques (2003, p. 161) afirma que "[...] a força do futebol no Brasil residiria também na capacidade de, num país de forte concentração de riquezas, pode proporcionar aos excluídos e injustiçados a experiência da vitória".

Desta forma, o futebol gaúcho também adquiriu elementos culturais atrelados ao imaginário do gaúcho. O mesmo discurso dominante se percebe nas narrativas relacionadas à Chapecoense, salientando questões como o "trabalho duro no treinamento", a "coragem de continuar" e também a "superação da equipe" quando se refere aos desfalques ou às estratégias que não deram certo. Existe uma clara relação de semelhança, tanto no discurso das equipes gaúchas como na equipe de Chapecó, onde estas questões são tratadas neste período de pré-temporada dos estaduais no bloco esportivo da
RBS TV de Chapecó. São estas também características atribuídas ao gaúcho, tido como herói que luta e supera com bravura. Estes elementos enunciativos contidos nos discursos do apresentador, no entanto, ficam mais evidentes em conteúdos relacionados à Chapecoense, não sendo excluídos dos textos da dupla Gre-Nal, porém restringidos a uma menor escala.

Há certa preocupação em respeitar a hegemonia da Chapecoense no tempo de exibição do bloco, na quantidade e detalhes da informação e nos discursos do bloco esportivo, que tornam a presença da dupla Gre-Nal algo secundário na lista de prioridades, porém indispensável. Este elemento de negação e de sobreposição de valores nos mostra uma característica emergente, embora também residual, da cultura gaúcha buscando espaço para se manter e se reafirmar enquanto cultura pertinente para aquele território. Uma disputa que, por abranger aspectos sociais, políticos e históricos, amplos e complexos, tornam a presença da cultura gaúcha um fenômeno curioso e atraente ao olhar da comunicação midiática, abrindo sempre espaço para novas e mais profundas abordagens.

\section{Considerações finais}

Esta análise apresentou alguns dos aspectos culturais existentes no município de Chapecó, muitas vezes ocultos em discursos ou, pelo contrário, fortemente manifestos em momentos específicos, como a Semana Farroupilha. Ficou evidente a influência da cultura gaúcha nos mais diversos aspectos sociais, inclusive na instalação das primeiras emissoras de televisão. Uma cultura que se mantém viva e expressada de várias formas, seja pelos CTGs ou na paixão pela dupla Gre-Nal, que acabou por abrir espaço para uma nova identidade futebolística regional. 
A Chapecoense, que hoje atua em espaços hegemônicos e dominantes, possivelmente, por ser ela um catalisador da identificação local, quiçá regional. O que a trama da cultura nos apresentou foi a emergência de um possível novo entendimento de identidade chapecoense, com vinculações próprias, mais independente e até orgulhosa, porém, não totalmente desvinculada de seu passado recente. Uma identidade que ainda se afirma pelo passado recente da colonização, mas que desenvolve nas conquistas atuais (na economia, organização social e até no esporte) força para se diferenciar perante as demais regiões de Santa Catarina.

Identificamos neste recorte do bloco esportivo do JA de Chapecó o processo de produção de um conteúdo midiático e alguns de seus elementos de mediação. Foi fundamental aprofundarmo-nos no contexto histórico de Chapecó e da constituição da mídia televisiva analisada para mapearmos a cultura gaúcha e seu papel na atualidade na identidade chapecoense. Obtivemos dados importantes através da rotina telejornalística, que negocia diariamente com o público aquilo que ele quer ver e aquilo que a emissora quer exibir.

Ao fim, pudemos expandir o olhar para possibilidades de se analisar a cultura e os aspectos identitários nos artefatos midiáticos como a televisão, entrelaçados com os sentidos do formato jornalístico. Acreditamos que o desenvolvimento de outros operadores analíticos, assim como a ampliação do embasamento teórico, trará definições mais concretas sobre a relação entre mídia e cultura na sociedade chapecoense. Neste sentido, esperamos estimular a pesquisa na área, bem como introduzir um percurso que poderá trazer importante recorte sobre a formação atual e o futuro da identidade cultural chapecoense.
Referências

CAVENAGHI, Beatriz; EMERIM, Cárlida. Os primórdios da televisão em Santa Catarina: mercado e produtos Revista Brasileira de História da Mídia (RBHM), v.3, n.1, jan. 2014.

ENNINGER, Rossana Zott. Análise cultural do telejornal local: representação e identidade na RBS TV Santa Rosa. 2015. 199 f. Tese (Mestrado em Comunicação Social) Faculdade de Comunicação Social, Universidade Federa de Santa Maria, Santa Maria, 2015.

HALL, Stuart. Da Diáspora: identidade e mediações culturais. Belo Horizonte: UFMG, 2006.

HALL, Stuart. A identidade cultural na pós modernidade. 4 ed. Rio de Janeiro: DP\&A, 2000.

HOBSBAWM, Eric; RANGER, Terence. A invenção das tradições. 3. ed. Rio de Janeiro: Paz e Terra, 2002.

LISBOA FILHO, Flavi Ferreira. Mídia regional:gauchidade e formato televisivo no Galpão Crioulo. 2009. 236 f. Tese (Doutorado em Ciências da Comunicação), Faculdade de Comunicação Social, Universidade do Vale do Rio dos Sinos, São Leopoldo, 2009.

MAIA, Paula. Telejornalismo e a construção da realidade: o teatro da vida real. 2002. Trabalho de Conclusão de Curso, Universidade do Oeste de Santa Catarina/Campus Chapecó, Chapecó, 2002.

MARQUES, José Carlos. O futebol em Nelson
Rodrigues: o óbvio ululante, o Sobrenatural de Almeida e outros temas. São Paulo: Educ/Fapesp, 2003.

SEVERO, Antunes; GOMES, Marco Aurélio. Memória da radiodifusão catarinense. Florianópolis: Insular, 2009.

SILVA, Edinéia Pereira da. A construção de uma memória gaúcha em Santa Catarina. 2010. $141 \mathrm{f}$. Dissertação (Mestrado em História), Faculdade e Filosofia em Ciências Humanas, Pontifícia Universidade Católica do Rio Grande do Sul, Porto Alegre, 2010.

WILLIAMS, Raymond. Cultura. Rio de Janeiro, Paz e Terra: 1992.

WILLIAMS, Raymond. Cultura e materialismo. Trad. André Glaser. São Paulo: Editora Unesp, 2011.

WILLIAMS, Raymond. La larga revolución. Buenos Aires: Nova Vision, 2003.

WILLIAMS, Raymond. Marxismo e literatura (W. Dutra, Trad.). Rio de Janeiro: Zahar, 1979.

WILLIAMS, Raymond. Base e superestrutura na teoria cultural (Bianca Ribeiro, Trad.). Revista USP: São Paulo, n. 66, pp. 209-224, 2005. http://dx.doi.org/10.11606/ issn.2316-9036.v0i66p209-224

Notas

1 Uma primeira versão deste texto foi apresentada ao $10^{\circ}$ Encontro Nacional de História da Mídia (Alcar) 2015, promovido pela Associação Brasileira de Pesquisadores da 
História da Mídia na Universidade Federal do Rio Grande do Sul, em Porto Alegre/RS.

2 Doutor em Ciências da Comunicação pela Universidade do Vale do Rio dos Sinos (UNISINOS). Professor do Programa de Pós-Graduação em Comunicação, do Programa de Pós-Graduação Profissionalizante em Patrimônio Cultural e do Departamento de Ciências da Comunicação da Universidade Federal de Santa Maria (UFSM Departamento de Ciências da Comunicação - Av. Roraima, 1000, prédio 21, sala 5138, Camobi. CEP: 97105-900, Santa Maria/RS). E-mail: flavilisboa@gmail.com.

3 Mestrando em Comunicação na Universidade Federal de Santa Maria - UFSM. Assessor de Imprensa da Universidade Comunitária da Região de Chapecó (UNOCHAPECÓ - Av. Senador Attilio Francisco Xavier Fontana E - até 799/800, Engenho Braun, CEP 89809-000, Chapecó/SC). E-mail: tchesco@gmail.com.

4 Este termo será utilizado neste estudo para trazer a ideia de fenômeno, como defende Lisbôa Filho (2009, p. 21), "[...] abrindo possibilidades para a investigação de qualidades, comportamentos, valores, maneiras de agir, sendo mais abrangente, permitindo a consideração de múltiplas formas discursivas de representação do que é gaúcho".

5 "la cultura de un período: el resultado vital específico de todos los elementos de la organización geral" (Williams, 2003, p. 57).
6 Entendida por Hobsbawm e Ranger (2002, p. 9) como "[...] um conjunto de práticas, normalmente reguladas por regras tácitas ou abertamente aceitas; tais práticas, de natureza ritual ou simbólica, visam inculcar certos valores e normas de comportamento através da repetição, o que implica, automaticamente, uma continuidade em relação ao passado".

7 Foi a segunda emissora de TV a ser fundada na cidade de São Paulo. Hoje é comandada por Roberto Marinho e atual Rede Globo.

8 Filiada desde 1967 à Rede Globo. Hoje possui 12 emissoras somente no estado do Rio Grande do Sul.

9 TV Planalto em 1980, que mais tarde seria comprada pelo Grupo Silvio Santos, tornando-se afiliada do Sistema Brasileiro de Televisão (SBT).

10 A Associação Chapecoense de Futebol foi fundada em 10 de maio de 1973.

11 Chapecó é considerada a capital do Oeste catarinense e tem 202.009 habitantes. Fonte: IBGE (Instituto Brasileiro de Geografia e Estatística) 2014, Diretoria de Pesquisas, Coordenação de População e Indicadores Sociais. 